\title{
The rabbit as a surgical model for early training stages of the laparoscopic Nissen fundoplication technique
}

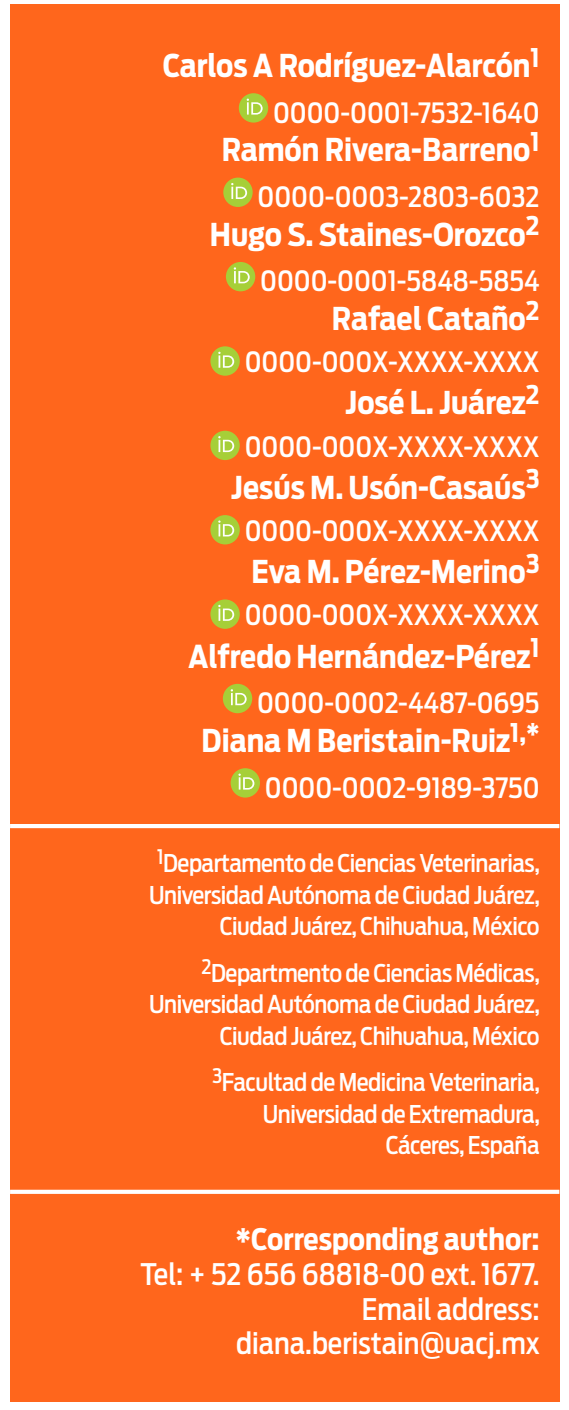

Accepted: $2019-05-29$ Published: 2019-06-28

Additional information and declarations can be found on page 10

@) Copyright 2019 Carlos A Rodríguez-Alarcón et al. open access $\boldsymbol{\odot}$

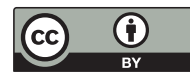

Distributed under Creative Commons CC-BY 4.0

\begin{abstract}
This study describes the advantages and disadvantages of using the rabbit as an animal model for surgical training in the Nissen laparoscopic fundoplication technique. Six New Zealand rabbits weighing between 2.5 and $3.5 \mathrm{~kg}$ were used. Nissen fundoplication was performed successfully in five out of six animals. Average procedure time was 47 minutes, with a maximum of 80 minutes for the first surgery and a minimum of 30 minutes for the last. Main advantages of the rabbit model are ease of animal restrain and low cost. The rabbit allows for the recreation of the human surgical environment, albeit showing a lower degree of difficulty. We thus consider this surgical model to be valuable only for skill development on basic stages of the laparoscopic Nissen fundoplication technique. For advanced stages of this surgical procedure, use of other animal models with further anatomical similarities to humans, such as the swine model, are recommended.
\end{abstract}

Keywords: Animal model; Nissen fundoplication; laparoscopy.

\section{Cite this as:}

Rodríguez-Alarcón CA, Rivera-Barreno R, Staines-Orozco HS, Cataño R, Juárez JL, Usón-Casaús JM, Pérez-Merino EM, Hernández-Pérez A, Beristain-Ruiz DM. The rabbit as a surgical model for early training stages of the laparoscopic Nissen fundoplication technique. Veterinaria México OA. 2019;6(2). doi: 10.22201/fmvz.24486760e.2019.2.458 


\section{Introduction}

Use of animal models is fundamental for laparoscopic surgical training. A learning curve in surgery is defined as the number of repetitions needed for a surgeon to successfully perform a procedure independently. ${ }^{1}$ However, due to inherent risks and ethical implications, the learning process should not take place directly with patients. ${ }^{2-4}$ The use of surgical simulators for training was emphasized in the year 2000 , also projecting the advancement of surgery as a science. "Laboratory work is essential for surgeon training; it provides understanding of diagnostic and therapeutic procedures, it creates scientific and inquisitive judgment on the surgeon, and it involves him in research, forcing him to participate in the progress of surgery as a science". 5

Development of laparoscopy has led to techniques that allow for surgeons to refine their skills. Inanimate simulators, anesthetized animals, and human cadavers have all been used as models, each with their respective array of advantages and disadvantages. The simpler inanimate models can be inexpensive, reusable and easy to move and store. However, they do not provide surgeons with a true sense of live tissue handling. Newer inanimate simulators are also reusable, and can improve surgeon sensitivity, but are costly. Anatomical accuracy of human cadavers allows for a more precise recreation of surgery. However, this model is expensive and only a limited number of surgeries can be performed. Access to live tissue, with similar characteristics to human tissue, can be achieved with anesthetized animal models. Working with animals also presents with potential real surgical situations during training such as hemorrhages. Nevertheless, cost can be steep, ethical implications must be considered, and special facilities and qualified staff are needed for housing and handling of individuals. Anesthetized animal models should therefore be employed for advanced procedures, where dissection skill development and bleeding control management are imperative. Conversely, for initial stages of surgical learning inanimate simulators are usually recommended. ${ }^{4,6}$ With these guidelines, a pyramidal model for teaching laparoscopic surgery has been proposed. ${ }^{3}$

Nonetheless, several authors have concluded that anesthetized animal models as laparoscopic surgery simulators constitute the most appropriate method for surgical training, despite disadvantages such as economic cost, anatomical differences with humans and ethical aspects..$^{7-11}$ Swine have been traditionally chosen as a surgical model due to anatomical similarities with humans. ${ }^{12,13}$ However, several differences between both species have also been described. ${ }^{14}$ For open and laparoscopic fundoplication surgery, dogs have been used as well. However, anatomical differences of the lower esophageal sphincter (LES) between dog breeds constitute a major limitation for this animal model. ${ }^{15,16}$ Indeed, some breeds have an extremely small abdominal esophagus, while others have a large abdominal esophageal segment and a completely abdominal LES. ${ }^{17}$ In addition to swine and dogs, researchers have sought other less expensive and easier to handle animal models including but not limited to, ferrets, rats, $18-21$ and rabbits. ${ }^{3,22-24}$

In humans, gastroesophageal reflux disease (GERD) is the most common disorder of the esophagus. Proton pump inhibitors are the mainstay for treatment of acid disorders such as GERD in humans. ${ }^{25}$ However, Nissen fundoplication is the gold standard for GERD treatment in patients that require antireflux surgery: 1) patients with symptoms who respond inadequately to proton-pump inhibitors (PPI); 2) patients that continue to have nonacid reflux, even eliminating heartburn 
by PPI; 3) patients with symptoms such as chest pain, cough, or wheezing, who have well-documented reflux events; 4) patients with secondary peptic stricture, Barrett's esophagus, or vocal cord injuries; and 5) patients with well-documented GERD, who wish to stop the chronic use of a PPI. ${ }^{26}$

In humans, Nissen fundoplication can be performed laparoscopically with five access ports, two of which are $10 \mathrm{~mm}$ in length and three that have a $5 \mathrm{~mm}$ span. In short, the procedure includes a secure crural closure and the development of a "floppy technique", which consists on performing a fundoplication equal to or less than $2 \mathrm{~cm}$ and 360 degrees. The $360^{\circ}$ Nissen fundoplication is accomplished when the anterior face of the gastric fundus is joined with the same anterior face with two or three suture points, one of which usually includes the anterior wall of the esophagus. Care must be taken to trap the anterior vagus nerve. To locate the gastric fundus, it is necessary to dissect the pars flaccida of the hepatogastric ligament and subsequently the peritoneum, which extends beyond the right crus. The left crus is subsequently exposed by extending the dissection through the top of the crural arch. Surgical dissection is then continued along the edge of the left crura, reaching the angle of His and finally the gastric fundus, which limits the inferior dissection. A blunt dissection (with closed laparoscopic clamps) of the pre-esophagic mediastinum is then started. This begins between the right crura and the esophagus and extends horizontally. The procedure is then repeated for the left crura.26,27

The objective of this research was to establish the advantages and disadvantages of using the rabbit as a surgical animal model for laparoscopic Nissen fundoplication training.

\section{Materials and methods}

This work was reviewed and approved by the Ethics and Animal Welfare Committee of the Universidad Autónoma de Ciudad Juárez, Mexico (CBE.ICB/001.01-25), and performed in compliance with the Mexican and American guidelines for animal research. ${ }^{28}$.

Laparoscopic Nissen fundoplication was performed on animals in a deep anesthetic plane using a combination of $0.4 \mathrm{mg} / \mathrm{kg}$ butorphanol (Torbugesic; Fort Dodge), 1 mg/kg acepromazine (PromAce; Fort Dodge), and 24 mg/kg ketamine (Inoketam 1000; Virbac) delivered intramuscularly. Rabbits had an endotracheal tube and were monitored by capnography and electrocardiography. The surgical team had four members that rotated roles with every surgery.

Six New Zealand rabbits (Oryctolagus cuniculus), between 2.5 and $3.5 \mathrm{~kg}$ of weight were used. Animals were laid supine with a $15^{\circ}$ anti-Trendelenburg position, and access ports were established. A first port was placed in the midline, between the last two pairs of mammary glands, where a $10 \mathrm{~mm}$ trocar for the lens was introduced by blunt dissection (Hasson technique). A $0^{\circ}$ telescope was used. The abdomen was insufflated through this port reaching a $10 \mathrm{mmHg}$ pressure. Once intra-abdominal vision was achieved, three additional $3 \mathrm{~mm}$ ports were established, one slightly cranial to the right and two slightly cranial to the left of the telescope (Fig. 1). The stomach, hiatal region and esophagus were identified. Conventional surgical instruments, such as Maryland forceps, needle holders and scissors, were used for the procedures. The surgeon utilized the two $3 \mathrm{~mm}$ ports located imme- 


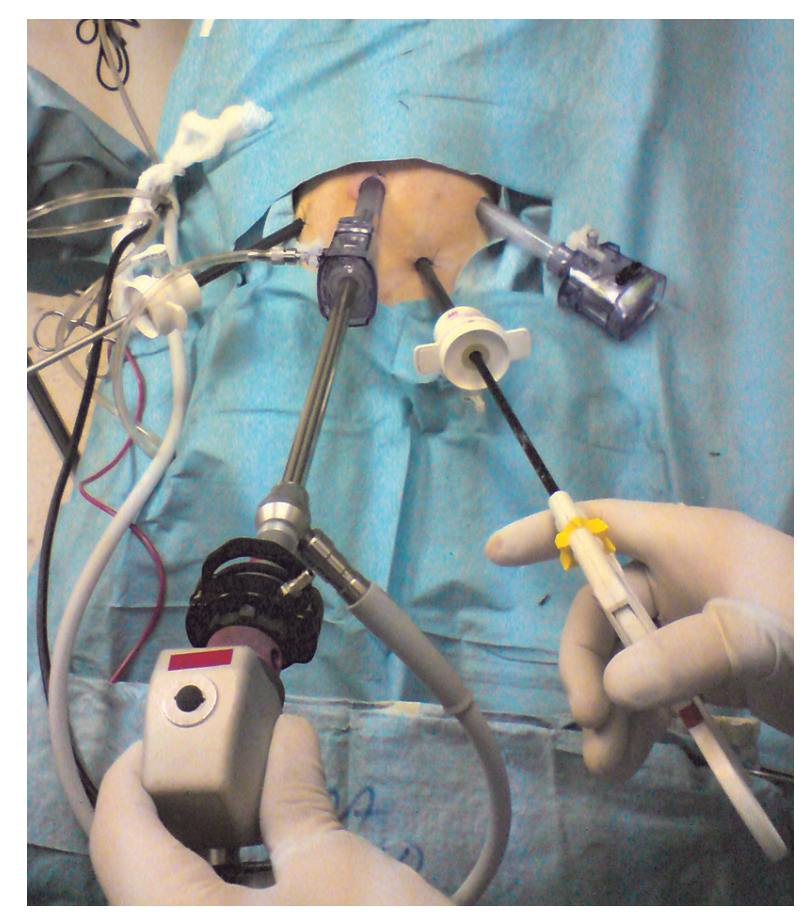

Figure 1. Photograph of port placement for laparoscopic Nissen fundoplication in rabbits.

diately adjacent to the telescope. In addition to handling the lens, the surgical assistant helped the surgeon with the esophagus dissection by using the farthest port from the left side, in order to restrain the stomach with forceps at the antrum. The stomach was pinched with forceps at the antrum to create traction. The esophagus was then dissected and separated from the diaphragmatic cruras. Care was taken to preserve the vagus nerves. The gastric fundus was subsequently passed behind the esophagus, and a $360^{\circ}$ "floppy" Nissen fundoplication fixed with three surgical knots was performed using a 3-0 poliglactin 910 suture. All animals were euthanized after surgery completion, and digestive tract patency and presence of leaks were assessed. Next, surgically concerned organs were resected for histopathological examination (Fig. 2).

Human and rabbit anatomical characteristics of the area of interest were compared only in successful surgeries ( $n=5)$, and a questionnaire was applied to each surgeon to evaluate the similarity of the rabbit as a surgical model and the difficulties it presents when compared to a human adult. Evaluated parameters were: surgical time, technical difficulties, and anatomical similarities to humans. Levels for technical difficulty were defined as: 1-2, impossible; 3-4, complicated; 5-6, moderate; 7-8, minor complications; and 9-10, no complications. ${ }^{10}$ For anatomical similarity levels were: $1-2$, no resemblance; $3-4$, slight resemblance; 5-6, moderate resemblance; 7-8, solid anatomical resemblance; and 9-10, identical anatomy.

For statistical analyses, SPSS for Windows 10.0 was used. The Cronbach's alpha coefficient was calculated for technical difficulty of the surgery. Average scores were determined for similarities of anatomical structures between the rabbit model and the adult human; and a correlation coefficient (ICC) was calculated to assess consistency between observers. ${ }^{29,30}$ 


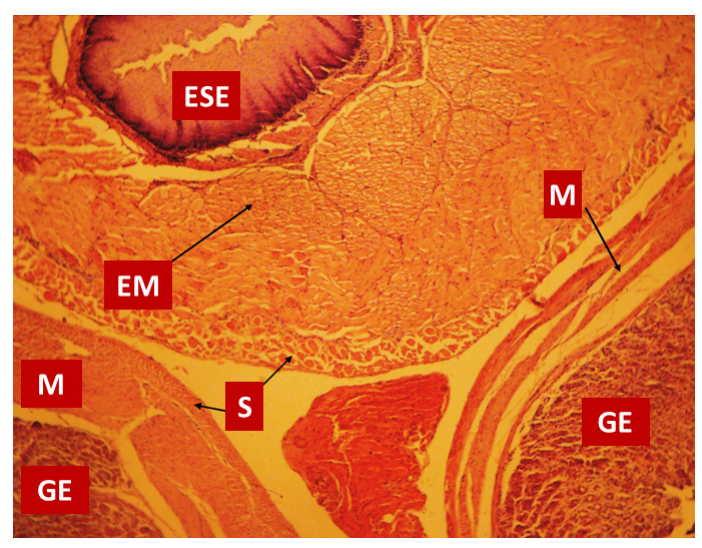

Figure 2. Histological section of esophagus and stomach after surgery. Note that the esophagus is localized between the two folds of the stomach. GE: gastric epithelium; ESE: esophageal keratinized stratified epithelium; EM: esophageal muscle; M: gastric muscle; S: serosa or adventitia (hematoxylin and eosin stain with $\times 40$ magnification).

\section{Results}

Five successful laparoscopic Nissen fundoplication procedures were performed in rabbits. Surgery times and surgical complications are presented in Table 1. Upon macroscopic inspection of the surgical zone, we found good surgical knot quality in all cases. In addition, the intervened segment of the digestive tracts consistently showed adequate patency without leakage. The average surgery time was 47 minutes, with a maximum of 80 minutes for the first surgery and a minimum of 30 minutes for the last surgery.

The mean score for technical difficulty over the five successful surgeries was $9.7 \pm 0.5$ (Cronbach's alpha $=0.8$ ). Average scores for anatomical similarity between rabbit and human anatomy are presented in Table 2 . The correlation coefficients (ICC) of the different anatomical sites was $r^{2}=0.839$. The anatomical comparison of the gastric fundus between rabbit and human had an average score of 8.60. Other anatomical structures had an average score as low as 6.50 (Table 2).

\section{Discussion}

Studies suggest that between 35 and 50 practice repetitions are necessary to develop the skills to reduce potential complications of laparoscopic Nissen fundoplication in humans. ${ }^{31,32}$ This study did not aim to establish that 6 surgical practices in rabbits were enough for a surgeon to perform the Nissen fundoplication technique in humans, but rather to establish anatomical similarities and differences between this animal model and humans.

The rabbit as an animal model for learning laparoscopic Nissen fundoplication presents advantages when compared to other animal models, such as low cost and ease of individual restrain and handling. The main disadvantages are anatomical differences with humans and required technical knowledge of anesthetic procedures in laboratory animals. The rabbit has been previously used as a model for learning laparoscopic surgery. ${ }^{8}$ The authors also concluded that the rabbit is a well-suited 
Table 1. Surgery time and surgical complications presented during laparoscopic fundoplication in a rabbit model.

\begin{tabular}{|c|c|c|}
\hline Rabbit Number & Surgery Time & Surgical Complications \\
\hline $\mathbf{1}$ & 80 minutes & Hepatic laceration \\
\hline $\mathbf{2}$ & 50 minutes & None observed \\
\hline $\mathbf{3}$ & Suspended & Gastric rupture \\
\hline $\mathbf{4}$ & 40 minutes & None observed \\
\hline $\mathbf{5}$ & 37 minutes & None observed \\
\hline 6 & 30 minutes & None observed \\
\hline
\end{tabular}

Table 2. Surgeon's scores for anatomical similarities between the rabbit and the adult human. A value of 1 was given for no similarity, whilst 10 was given for identical anatomy. Averages for each anatomical structure and a global correlation coefficient for the scores is presented.

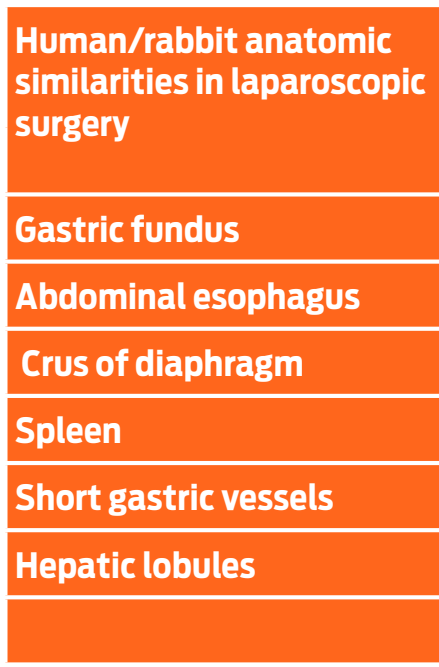

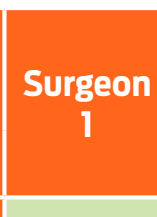

8

7

7

7

7

6

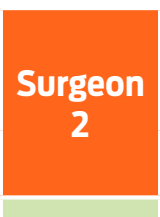

9

7

6

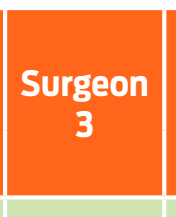

9

6

5

5

6

6

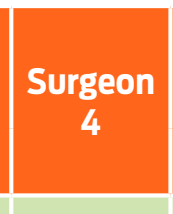

9

6

5

5

5

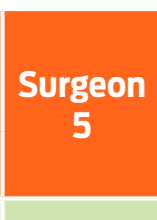

8

6

5

5

6

6

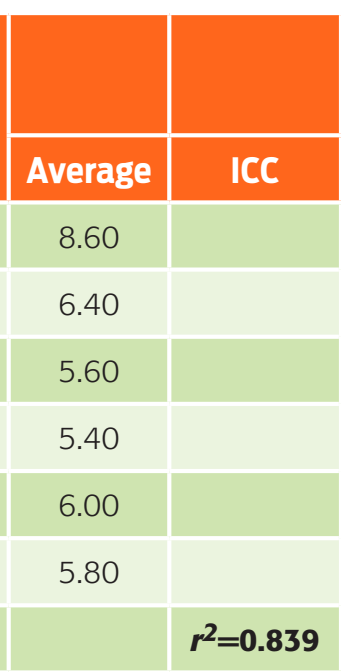

model for teaching and training in laparoscopic procedures, mainly due to the previously stated reasons of low cost and ease of handling. Several surgical procedures can indeed be performed in rabbits via laparoscopy, but the main objective of our work was not to make comparisons between different animal models, but rather, to compare technical difficulties when performing the Nissen fundoplication technique in rabbits and humans.

Our results support the rabbit as a suitable animal model for the teaching and practice of Nissen fundoplication by laparoscopy. However, it might not be appropriate for human surgeons to develop the more complex skills required to master the technique, due to anatomical differences between both species (Table 2). In effect, for early learning stages, the rabbit was an excellent model in which to perform knots and the periesophageal wrapping cuff using laparoscopic instruments (Figs. 3-7). Formation of knots is one of the most difficult elements of the technique in human surgery. Consequently, preliminary training with simulators is recommended. 1,3 Indeed, ligation of gastric short vessels is considered to be the most difficult maneuver of this surgery. ${ }^{33}$ In addition, ligation of the short vessels is 


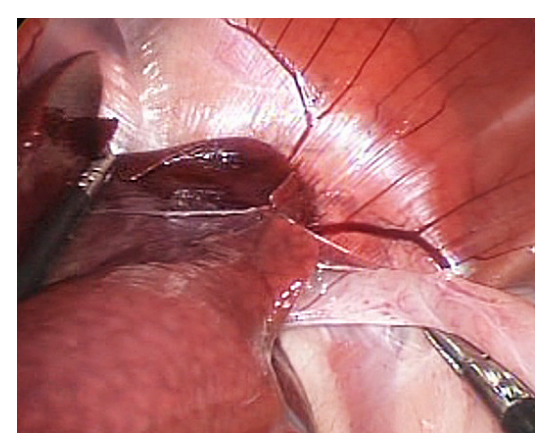

Figure 3. Dissection of the abdominal esophagus.

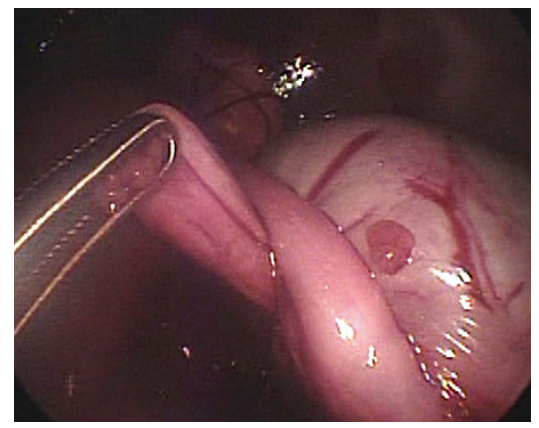

Figure 5. The fundus is passed completely below the esophagus.

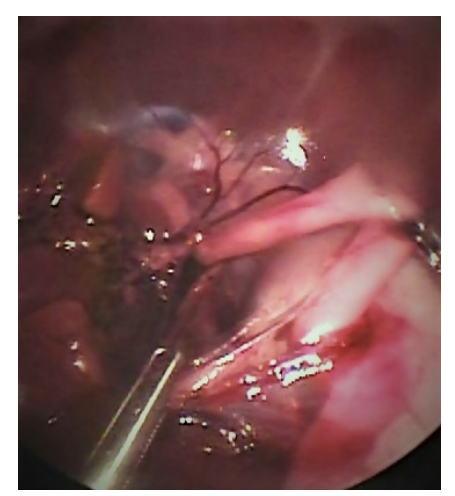

Figure 4. Fundus clamping below the esophagus.

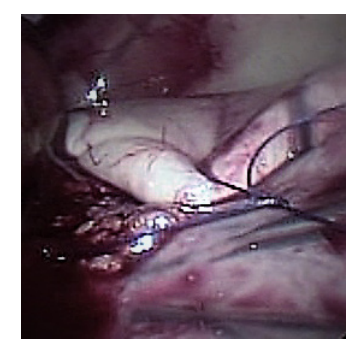

Figure 6. Suture of serosa of the fundus around the esophagus.

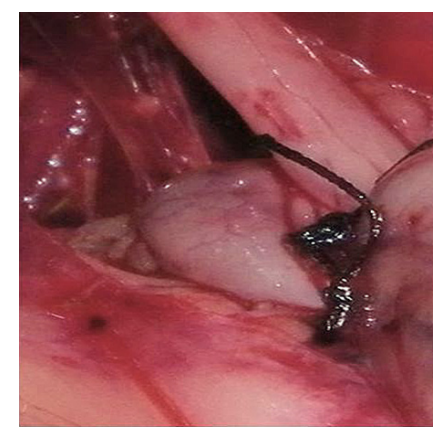

Figure 7. Fundoplication completion. 
essential for fundoplication because it can decrease morbidity of patients undergoing laparoscopic surgery. ${ }^{34}$ However, it is worth mentioning that there is a NissenRossetti procedure in which ligation of the short gastric vessels is not necessary. ${ }^{6}$ Moreover, an easier and faster Nissen fundoplication technique allows to avoid the cutting of the short gastric vessels altogether. ${ }^{35}$

An important difference between human and rabbit anatomy is that the liver of the latter is lobulated. Consequently, use of liver separators when performing Nissen fundoplication in rabbits is recommended. ${ }^{22}$ In this study, laparoscopic forceps were used for separation of liver lobules. Careful handling of liver was essential since the parenchyma is quite friable. As done by other researchers, we dissected the left and median hepatic ligaments, which are closely attached to the abdominal esophagus. ${ }^{22}$ Furthermore, we separated the phreno-esophageal membrane, which was an easy process because it has no fat. Our surgical procedure differed from that of Luks et al. ${ }^{22}$ since we did not consider that the diaphragmatic cruras were difficult to dissect. This was probably due to their smaller size in the rabbit.

A further consideration is that it was not necessary to perform any procedure to gain additional length of the esophagus from the mediastinum in rabbits. In fact, this is a critical part of Nissen fundoplication in humans, and potentially the most hazardous. ${ }^{36-38}$ This is a disadvantage when using the rabbit for training when compared to other animal models such as the pig, in which this technique has been previously described. ${ }^{39}$

The fact that the rabbits presented a full stomach, nonetheless it did not have a negative impact on surgery performance as the fundus is easily manipulated to complete fundoplication. However, this means that the stomach can be easily ruptured during handling. One of the rabbits in this study presented a gastric rupture, which we believe was due to excessive air inside the stomach. Air was initially introduced to the stomach to perform a preoperative endoscopy as a control to identify this anatomical structure. However, a gastric tube was then placed, seemingly unsuccessfully, to remove all air before surgery. We thus decided not to perform any other pre-surgical endoscopies. Also, we recommend proficiency regarding gastro-esophageal rabbit anatomy before any attempt to perform laparoscopic Nissen fundoplication in this model. ${ }^{40,41}$ Another anatomical difference that is worth noting is the laxity of the abdominal muscles of rabbits, which directed the surgeons in this study to favor the open Hasson technique to introduce the first trocar to create the pneumoperitoneum.

Rabbit surgery requires technical knowledge of anesthetic procedures, hence a veterinary team with experience in laboratory animal management. ${ }^{42}$ Trans-surgical management of rabbits requires endotracheal intubation, to counteract the effect of the pneumoperitoneum; failure to do so will cause respiratory failure and death. 43,44

\section{Conclusion}

The main advantages of rabbits as surgical animal models are low cost and ease of animal restrain. In addition, the rabbit model allows for a partial recreation of the adult human surgical environment, albeit with a lower degree of difficulty. Thus, we believe it to be useful for reproducing early stages of the Nissen fundoplication 
technique. However, there also are disadvantages, such as size, difficulty in anaesthetic procedures and poor gastric emptying. In addition, there are anatomical differences with humans, including a short abdominal oesophagus and a lobulated liver, both of which can lead to the two major complications presented in this research. Therefore, we believe the rabbit to be a useful surgical model only for the development of surgical skills in the early stages of the laparoscopic Nissen fundoplication technique. However, for more advanced training levels, use of other animal models with further anatomical similarities to an adult human, such the swine model, are necessary. 


\section{Funding}

This study was funded by PROMEP, Mexico.

\section{Acknowledgements}

The authors would like to thank Dr. Santiago Andres for his collaboration in the statistical analyses, Dr. Isaac Jardín and Mr. Manuel Contreras Escobedo (Jefatura de Producción Multimedia, UACJ) for image processing, and Nurse Lilia Terrazas for technical assistance during surgery.

\section{Conflicts of interest}

The authors declare that they do not have any conflicts of interest..

\section{Author contributions}

All authors critically reviewed and edited the manuscript.

C.A.R.A : Design and drafting the manuscript and established the surgical model

R.R.B; J.M.U.C and E.M.P.M.: Design the manuscript and established the surgical model

H.S.S.O; R.C. and J.L.J.: Established the surgical model and evaluated surgery

A.H.P: established the surgical model and anesthetized the animals

D.M.B.R.: Design and drafting the manuscript and carried out the statistical analyzes.

\section{References}

1. Latiff A. La curva de aprendizaje en la cirugía: ¿qué es?, ¿cómo se mide? Rev Col Uro. 2005;14(1):15-7.

2. Aggarwal R, Darzi A. Technical-skills training in the 21st century. N Engl J Med. 2006;355(25):2695-6.

3. Usón Gargallo J, Sánchez Margallo FM, Díaz-Güemes Martín-Portugués I, Loscertales Martín de Agar B, Soria Gálvez F, Pascual Sánchez-Gijón S. Modelos experimentales en la cirugía laparoscópica urológica. Actas Urol Esp. 2006;30(5):443-50.

4. Berg DA, Milner RE, Fisher CA, Goldberg AJ, Dempsey DT, Grewal H. A cost-effective approach to establishing a surgical skills laboratory. Surgery. 2007;142(5):712-21.

5. Gutiérrez $C$. The experimental model in surgery: historical perspective. Cir Gen. 2000;22(3):272-8.

6. Rendón CE, Hernández CA, Villanueva SKR. Huizar SP, Mata QC, Dorado RJD, et al. Funduplicatura laparoscópica simplificada: resultados de 302 casos. Rev Mex Cir Endosc. 2004;5(1):44.

7. Gutt CN, Riemer V, Brier C. Berguer R, Paolucci V. Standardized technique of laparoscopic surgery in the rat. Dig Surg. 1998;15(2):135-9.

8. Valdivieso J, Contador M. The Rabbit: A Good Animal Model for Teaching and Training in Pediatric Laparoscopic Surgery. Pediatr Endosurg Innov Techniques. 2003;7(3):303-7.

9. Gomez-Fleitas $\mathrm{M}$. The need for changes in surgical training: an unresolved problem in endoscopic surgery. Cir Esp. 2005;77(1):3-5.

10. Pérez-Merino EM, Usón-Casaús JM, Zaragoza-Bayle C, Rivera-Barreno R, Rodríguez-Alarcón CA, Palme R, et al. Development of an optimal diaphragmatic hernia rabbit model for pediatric thoracoscopic training. Exp Anim. 2014;63(1):93-8. 
11. Usón-Casaús J, Pérez-Merino EM, Rivera-Barreno R, Rodríguez-Alarcón CA, Sánchez-Margallo FM. Evaluation of a Bochdalek diaphragmatic hernia rabbit model for pediatric thoracoscopic training. J Laparoendosc Adv Surg Tech A. 2014;24(4):280-5.

12. Doi T, Ichikawa S, Miyano G, Lane GJ, Miyahara K, Yamataka A. A new technique for preventing wrap disruption/migration after laparoscopic nissen fundoplication: an experimental study. J Laparoendosc Adv Surg Tech A. 2008;18(1):179-82.

13. Wachowiak R, Krauss A, Donaubauer B, Muensterer OJ. Cardiac yield pressure measurement in an infant porcine model: a novel technique to evaluate the quality of laparoscopic fundoplication. J Laparoendosc Adv Surg Tech A. 2008;18(6):887-90.

14. Rodríguez-García Jl, Turienzo-Santos E, Vigal-Brey G, Brea-Pastor A. Formación quirúrgica en simuladores en centros de entrenamiento. Cir Esp. 2006;79(6):342-8.

15. Shirazi SS. Long-term effect of Nissen fundoplication in young puppies. J Pediatr Surg. 1980;15(6):869-71.

16. Cox MR, Franzi SJ, Martin CJ. The effect of fundoplication on the motility of the canine lower oesophageal sphincter. Aust N Z J Surg. 2000;70(1):68-72.

17. Pratschke KM, Fitzpatrick E, Campion D, McAllister H, Bellenger CR. Topography of the gastro-oesophageal junction in the dog revisited: possible clinical implications. Res Vet Sci. 2004;76(3):171-7.

18. Goldenberg A, Lobo E, Marcondes EJ. Louzada M, Barbosa CDL. Proposition of laparoscopy in rats. Acta Cir Bras. 1997;12(4):219-20.

19. Oliveira FM, Oliveira Jr LC, Costa VA, Carreiro MC, Guimarães P. Experimental model of laparoscopic partial hepatectomy in rats. Acta Cir Bras. 2003; 18(3):257-61.

20. Melo-Filho AA, Vinagre AM, Collares EF, Bustorff-Silva JM. Effect of different types of fundoplication on the gastric emptying of liquids and gastric compliance in rats. J Pediatr Surg. 2005;40(10):1551-6.

21. O'Rourke RW, Kim CY, Chang EY, Hunter JG, Jobe B. Alncorporation of Nissen fundoplication in a rat model of duodenoesophageal reflux. Surg Endosc. 2007;21(3):467-70.

22. Luks Fl, Peers KH, Deprest JA, Lerut TE. Gasless laparoscopy in infants: the rabbit model. J Pediatr Surg. 1995;30(8):1206-8.

23. Terzioglu T, Yalti, T, Tezelman S, Unal S. Gastroesophageal reflux and a comparison of the different antireflux procedures following esophagomyotomy: an experimental study in rabbits. Surg Today. 1998;28(8):816-21.

24. Esposito C, Escolino M, Draghici I, Cerulo M, Farina A, De Pascale T, et al. Training Models in Pediatric Minimally Invasive Surgery: Rabbit Model Versus Porcine Model: A Comparative Study. J Laparoendosc Adv Surg Tech A. 2016;26(1):79-84.

25. Faruqui AA. Need of Combining Proton Pump Inhibitors with Prokinetics: A Prospective Observational Survey Conducted in India. J Medicine. 2018;19(2):74-8.

26. The SH, Hunter JG. Laparoscopic Nissen fundoplication. Oper Tech Thorac Cardiovasc Surg. 2006;11:218-31.

27. Csendes A, Díaz JC, Burdiles P, Maluenda F. Detalles técnicos y morbimortalidad de la fundoplicatura de Nissen laparoscópica en 503 pacientes con reflujo gastroesofágico. Rev Chil Cir. 2016;68(2):143-9. 
28. National Research Council. Guide for the care and use of laboratory animals. Washington, DC: National Academies Press; 2011.

29. Berk RA. Generalizability of behavioral observations: A clarification of interobserver agreement and interobserver reliability. Am J Ment Defic. 1979; 83:460-472.

30. Grewal DS, Stinnett SS, Folgar FA, Schneider EW, Vajzovic L, Asrani S, et al. A Comparative study of rebound tonometry with tonopen and goldmann applanation tonometry following vitreoretinal surgery. Am J Ophthalmol. 2016;161:22-8.

31. Watson DI, Baignie RJ, Jamieson GG. A learning curve for laparoscopic Nissen fundoplication: definable, avoidable, or a waste of time? Ann Surg. 1996;224(2): 198-203.

32. Peters JH, Demeester TR, Crookes P, Oberg S, de Vos Shoop M, Hagen JA, Bremner CG. The treatment of gastroesophageal reflux disease with laparoscopic Nissen fundoplication: prospective evaluation of 100 patients with typical' symptoms. Ann Surg. 1998;228(1):40-50.

33. López CJA, Quiñónez MS, Guzmán CF, Covarrubias MA, Lopez DJM. Rev Mex Cir Endosc. 2004;5:32.

34. Cohen Z, Fishman S, Yulevich A, Kurtzbart E, Mares AJ. Nissen fundoplication and Boix-Ochoa antireflux procedure: comparison between two surgical techniques in the treatment of gastroesophageal reflux in children. Eur J Pediatr Surg. 1999;9(5):289-93.

35. Liu DC, Lin T, Statter MB, Glynn L, Melis M, Chen Y, et al. Laparoscopic Nissen fundoplication without division of short gastric vessels in children. J Pediatr Surg. 2006;41(1):120-5.

36. Minjarez C, Jobe BA. Surgical therapy for gastroesophageal reflux disease. GI Motility Online. 2006; doi:10.1038/gimo56

37. Bochkarev V, Lee YK, Vitamvas M, Oleynikov D. Short esophagus: how much length can we get? Surg Endosc. 2008;22(10):2123-7.

38. Kunio NR, Dolan JP, Hunter JG. Short esophagus. Surg Clin North Am. 2015;95(3):641-52.

39. DeMeester SR, Sillin LF, Lin HW, Gurski RR. Increasing esophageal length: a comparison of laparoscopic versus transthoracic esophageal mobilization with and without vagal trunk division in pigs. J Am Coll Surg. 2003;197(4):558-64.

40. Rodríguez-Alarcón CA, Pérez E, Martín U, Rivera R, Hernández A, Vivo J, et al. Morphometry of the abdominal esophagus and stomach of the rabbit. laparoscopyc surgery application. Int J Morphol. 2010;28(1):27-31.

41. Alves JR, Lopes LR, Sasasaki T. Estudio Morfométrico del Estómago en Conejos. Int J Morphol. 2014;32(1):227-31.

42. Lafferty K. Anesthetic management of rabbits and ferrets. In: Smith LJ, editor. Questions and answers in small animal anesthesia. Hoboken: John Wiley \& Sons; 2015. p. 343-54. doi: 10.1002/9781118912997.ch43

43. O'Leary E, Hubbard K, Tormey W, Cunningham AJ. Laparoscopic cholecystectomy: haemodynamic and neuroendocrine responses after pneumoperitoneum and changes in position. Br J Anaesth. 1996;76(5):640-4.

44. Fernandes CR, Souza-Filho LM, Gomes JM, Messias EL, Escalante RD. Consequences of the addition of nitrous oxide to anesthesia during pneumoperitoneum in videolaparoscopic surgeries. Rev Bras Anestesiol. 2007;57(1):1-7. 